\title{
POMGnT1 mutation and phenotypic spectrum in muscle- eye-brain disease
}

\author{
C Diesen, A Saarinen, H Pihko, C Rosenlew, B Cormand, W B Dobyns, J Dieguez, L Valanne, \\ T Joensuu, A-E Lehesjoki
}

J Med Genet 2004;41:e1 15 (http://www.jmedgenet.com/cgi/content/full/41/10/e115). doi: 10.1136/jmg.2004.020701

M uscle-eye-brain disease (MEB; OMIM 253280) was first described in 1977 in Finland, ${ }^{1}$ where it is enriched because of founder effect and genetic isolation. ${ }^{2}$ MEB is now known to occur throughout the world, but Finland remains the country with the largest group of MEB patients.

MEB patients present as floppy infants with visual problems and severe mental retardation. The hypotonia is partly caused by muscular dystrophy and partly by cerebral dysfunction. Hypotonia is replaced by spasticity and contractures with increasing age. ${ }^{13}$ Visual failure is the result of progressive myopia, retinal degeneration, and congenital glaucoma. Juvenile cataracts develop by the age of 10 years. The presence of giant visual evoked potentials is an important diagnostic feature. ${ }^{4}$ The typical central nervous system malformation revealed by magnetic resonance imaging (MRI), referred to as "cobblestone complex", ${ }^{5}$ consists of cobblestone cortex, midline deformities, flat brain stem, mild cerebellar hypoplasia, and cerebellar cortical cysts. ${ }^{6}$ Microscopically the cortex is disorganised, with an overgrowth of glia forming a thick membrane on the brain surface. $^{7}$

The combination of muscular dystrophy and a severe neuronal migration defect is not exclusive for MEB, but is also seen in Walker-Warburg syndrome (WWS; OMIM $236670^{8}$ ) and Fukuyama congenital muscular dystrophy (FCMD; OMIM 253800 ${ }^{\circ}$. The recent molecular genetic findings have provided an explanation as to why the distinct clinical features are partially shared in these three diseases. The $M E B$ gene encodes a protein $O$-mannose b-1, 2- $N$ acetylglucosaminyltransferase (POMGnTl). ${ }^{10}$ Mutations in another enzyme involved in $O$-mannosylation, the $O$-mannosyltransferase (POMT1), were recently found in a group of WWS patients. ${ }^{11}$ Fukutin, encoded by the FCMD gene, ${ }^{12}$ is strongly suspected to play a role in glycosylation. ${ }^{13}$ The unifying feature in all these disorders is deficient posttranslational glycosylation of $\alpha$-dystroglycan, ${ }^{11}{ }^{14-16}$ suggesting that impaired function of $\alpha$-dystroglycan plays a critical role in their pathogenesis. Recently, mutations in the LARGE gene were reported in a patient with congenital muscular dystrophy, profound mental retardation, white matter changes, and subtle structural abnormalities on brain MRI, suggesting abnormal neuronal migration. ${ }^{17} L A R G E$ is the human homologue of mouse Large, which is mutated in the myodystrophy mouse. ${ }^{18}$ Compatible with findings in the mouse, the human patient showed reduced immunolabelling of $\alpha$-dystroglycan, adding a new member to the group of disorders characterised by congenital muscular dystrophy and a neuronal migration defect caused by deficient glycosylation of $\alpha$-dystroglycan.

Thirteen MEB causing mutations covering the whole POMGnTl gene have previously been reported. ${ }^{10}{ }^{19}$ Ten of these predict protein truncation, while three are missense mutations. Expression studies of mutant POMGnTl proteins

\section{Key points}

- Mutations located throughout the POMGnTl gene encoding protein O-mannose b-1, 2-N-acetylglucosaminyltransferase underlie muscle-eye-brain disease (MEB), an autosomal recessive disorder characterised by brain malformation, congenital muscular dystrophy, and ocular abnormalities.

- $M E B$ is enriched in the Finnish population, where a previously described mutation, c. 1539+1G $\rightarrow A$, accounts for $99 \%$ of the MEB chromosomes.

- Nine new POMGnT1 mutations in 10 patients of various ethnic origins are described, adding the number of reported MEB associated POMGnT1 mutations to 22.

- The clinical phenotypes of the non-Finnish patients in this study and published previously fall within the variation observed in the Finnish patients who are homozygous for the founder mutation, indicating that in addition to mutations in the POMGnTl gene, other genetic and environmental factors influence the MEB phenotype.

harbouring patient mutations suggest that MEB is inherited as a loss of function of POMGnTl. ${ }^{10}{ }^{20}$ We screened the exons and exon-intron boundaries of POMGnTl in 16 MEB patients from 14 families. We identified nine new mutations and found that the mutation affecting the splice donor site in intron 17, reported previously in three patients, is the prevalent mutation in the Finnish MEB patients.

\section{METHODS}

\section{Patients and families}

Fourteen Finnish families with a total of 19 patients, 25 parents, and four healthy siblings were included in the study. Of these families, one was consanguineous, the parents being second cousins. In addition, 12 non-Finnish families with a total of 14 patients, 20 parents, and six healthy siblings were studied. These patients originated from the USA (six patients from five families), Sweden (two patients from two families), Estonia (one patient), Norway (one patient), Italy (one patient), Israel (two patients, Christian Arab siblings ${ }^{21}$ ), and Spain (one patient).

\footnotetext{
Abbreviations: CDG, congenital disorder of glycosylation; $\mathrm{CEPH}$, Centre d'Etude du Polymorphisme Humaine; FCMD, Fukuyama congenital muscular dystrophy; MEB, muscle-eye-brain disease; PCR, polymerase chain reaction; RT-PCR, reverse transcriptase polymerase chain reaction; SSCP, single strand conformation polymorphism; WWS, Walker-Warburg syndrome
} 


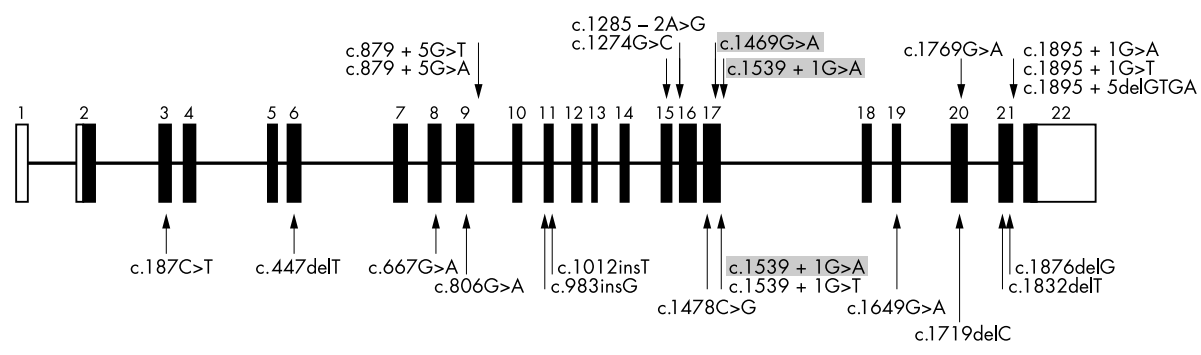

Figure $1 P O M G n T 1$ mutations associated with muscle-eye-brain disease (MEB). Schematic representation of the genomic structure of the POMGnT1 gene showing the positions of MEB associated mutations. Those identified in the present study are marked above the gene, those identified previously ${ }^{10} 19$ are indicated below the gene. Mutations identified in more than one family are shaded.

Finnish controls included 154 individuals, of whom 98 represented regions where the incidence of MEB is higher than the average 1:50 000 in Finland. In addition, DNA samples from 96 unrelated $\mathrm{CEPH}$ grandparents (CEPH; Centre d'Etude du Polymorphisme Humaine) of family members were used as controls. All the identified changes were also analysed in a panel of 40 patients with a clinical diagnosis of WWS/MEB.

The study was approved by the ethics committee of the Helsinki University Central Hospital.

\section{PCR and RT-PCR}

The POMGnTl gene was analysed for mutations by sequencing the coding region and the exon-intron boundaries of the 21 coding exons from polymerase chain reaction (PCR) amplified genomic DNA. The primers were designed from genomic sequence (GenBank AL672043.15) using the Primer3 program (http://www-genome.wi.mit.edu/cgi-bin/ primer/primer3_www.cgi). The optimal working conditions were determined by running a gradient PCR. The primer sequences are available on request from the authors.

The PCR reactions were carried out in a final volume of 25 $\mu \mathrm{l}$ containing $10 \mathrm{ng}$ DNA, $5 \mathrm{pmol}$ of both forward and reverse primers, $0.2 \mathrm{mM}$ dNTP (Finnzymes, Espoo, Finland), $1 \times$ PCR buffer, and $1 \mathrm{U}$ Ampli Taq Gold ${ }^{\mathrm{TM}}$ polymerase (PE Applied Biosystems, Norwalk, Connecticut, USA). The PCR was run with the following cycling profile: 10 minutes' denaturation at $95^{\circ} \mathrm{C}, 35$ cycles of denaturation at $95^{\circ} \mathrm{C}$ for 45 seconds, annealing at primer specific annealing temperature (50$64^{\circ} \mathrm{C}$ ) for 45 seconds, and extension at $72^{\circ} \mathrm{C}$ for 45 seconds, followed by a final extension step at $72^{\circ} \mathrm{C}$ for 10 minutes. The PCR products were run on a $2 \%$ SeaKem LE agarose gel (BioWhittaker Molecular Applications, Rockland, Maine, USA) and visualised with ethidium bromide staining. PCR products were purified with enzymatic ExoI/SAP treatment (USB) and then sequenced using an ABI 3100 or ABI 3730 DNA analyser (PE Applied Biosystems). Sequence chromatograms were analysed with Sequencher 4.0 program (Gene Codes Corporation, Ann Arbour, Michigan, USA).

Total cell RNA was prepared from blood samples or Epstein-Barr virus transformed lymphoblastoid cells from patients, carriers, and controls using the PAXgene blood RNA validation kit (PreAnalytiX, Qiagen Inc, Valencia, California, USA) and the Qiagen Total RNA Kit, respectively. Reverse transcription (RT-PCR) was done using the 1st-Strand cDNA synthesis kit (Amersham Biosciences, Amersham, Buckinghamshire, UK) through oligo-dT or random hexamer priming (Promega, Madison, Wisconsin, USA).

Patient, family, and control samples were analysed for the identified changes either by single strand conformation polymorphism (SSCP), restriction digestion of amplified genomic DNA, or sequencing, or a combination of these. A panel of 40 WWS/MEB patient samples was analysed by sequencing. The identified sequence variants were numbered using GenBank NM_017739 as a reference sequence, with nucleotide 142 corresponding to +1 .

Mutations c. $879+5 \mathrm{G} \rightarrow \mathrm{T}, \quad$ c. $879+5 \mathrm{G} \rightarrow \mathrm{A}, \quad$ c. $1469 \mathrm{G} \rightarrow \mathrm{A}$, c. $1895+\mathrm{lG} \rightarrow \mathrm{T}$, and c. $1895+\mathrm{lG} \rightarrow \mathrm{A}$ were analysed by SSCP. The denatured PCR amplified products were separated on either $0.5 \times \mathrm{MDE}^{\mathrm{TM}}$ gel (FMC) at $3 \mathrm{~W}$ or $0.7 \times \mathrm{MDE}^{\mathrm{TM}}$ gel (FMC) at $5 \mathrm{~W}$ for 17-18 hours, and the alleles were visualised by silver staining. ${ }^{22}$

Mutations c.1274G $\rightarrow$ C, c. $1285-2 \mathrm{~A} \rightarrow \mathrm{G}$, c. $1539+\mathrm{lG} \rightarrow \mathrm{A}$, and c. $1769 \mathrm{G} \rightarrow \mathrm{A}$ were screened by restriction digestion of PCR amplified genomic DNA using the following enzymes, respectively: TaqI, SmaI, PmlI and AvaII (all enzymes from New England BioLabs, Beverly, Massachusetts, USA). The digested products were run on a $2 \%$ SeaKem LE agarose gel (BioWhittaker Molecular Applications) and visualised with ethidium bromide staining.

Control samples for mutation c.1895+1_4delGTGA were analysed by sequencing using an ABI3730 DNA analyser (PE Applied Biosystems). Sequences were analysed with Sequencher 4.0 program (Gene Codes Corporation).

\section{RESULTS}

We screened the whole 1983 base pair (bp) coding region and the exon-intron boundaries of POMGnTl in two Finnish patients representing different haplotypes, as well as in 14 non-Finnish patients from 12 families with a clinical diagnosis of MEB. The identified mutations are summarised in table 1 and fig 1 . In addition, a previously identified coding SNP (rs2292487) and several flanking intronic polymorphisms (data not shown) in POMGnTl were identified. Haplotype analysis in Finnish patients (data not shown) suggested the existence of two mutations. A substitution of the highly conserved nucleotide $G$ with nucleotide $A$ at the splice donor site of intron 17 (c.1539+lG $\rightarrow$ A; reported by Yoshida et $a l^{10}$ and Taniguchi et $a l^{19}$ as IVS17+lG $\rightarrow$ A) was found to be associated with the founder haplotype (22 of 23 haplotyped chromosomes) in the Finnish patients. The mutation was found to result in skipping of the upstream exon 17 (data not shown), predicting an in-frame deletion of 42 amino acids (aa 472-513 in NP_060209). The mutation cosegregated with the disease phenotype in the Finnish MEB families, where 18 patients $(1-17,33)$ from 13 families had it in homozygous form, while one patient (18) had it in heterozygous form. The other mutation in patient 18 was a $G$ to $\mathrm{T}$ substitution in intron $9,5 \mathrm{bp}$ from the exon-intron boundary (c.879+5G $\rightarrow$ T). RT-PCR analysis of lymphoblastoid cell RNA from this patient (data not shown) showed that the mutation abolishes the donor splice site in intron 9 and a cryptic donor site is used instead, resulting in the retention of the first 25 nucleotides from intron 9 in the mature mRNA. The mutation produces an insertion of seven new amino acids after proline 293, followed by a stop codon (Human Genome Variation Society recommended us to use (p.Pro293_Leu294ins7X8) instead of (p.Pro293_Leu294ins7; 
Table 1 POMGnT1 mutations identified in 33 patients with muscle-eye-brain disease of various ethnic origins

\begin{tabular}{|c|c|c|c|}
\hline \multirow[b]{2}{*}{ Patient/origin } & \multicolumn{3}{|l|}{ Mutations } \\
\hline & Nucleotide change & Exon/intron & Predicted effect \\
\hline $\begin{array}{l}\text { 1-17, 33/Finland } \\
\text { 18/Finland } \\
\text { 19/Sweden } \\
\text { 20/Sweden } \\
\text { 21/Norway } \\
\text { 22/Estonia } \\
\text { 23/USA } \\
\text { 24/USA } \\
\text { 25/USA } \\
\text { 26/USA } \\
\text { 27, 28/USA } \\
\text { 29, 30/Israel } \\
\text { 31/Spain } \\
\text { 32/Italy }\end{array}$ & 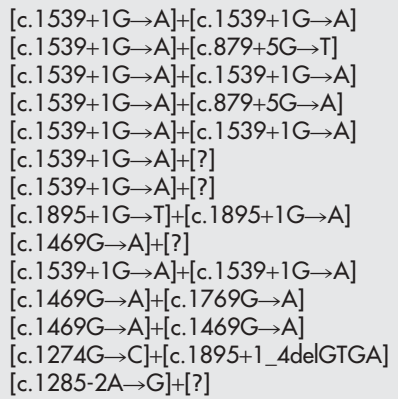 & $\begin{array}{l}\text { IVS17+IVS17 } \\
\text { IVS17+IVS9 } \\
\text { IVS17+IVS17 } \\
\text { IVS17+IVS9 } \\
\text { IVS17+IVS17 } \\
\text { IVS17+? } \\
\text { IVS17+? } \\
\text { IVS21+IVS21 } \\
\text { E17+? } \\
\text { E17+E17 } \\
\text { E17+E20 } \\
\text { E17+E17 } \\
\text { E15+IVS21 } \\
\text { IVS15+? }\end{array}$ & $\begin{array}{l}\text { [p.Leu472_His513del]+[p.Leu472_His513del] } \\
\text { [p.Leu472_His513del]+[p.Pro293_Leu294ins7;p.301X] } \\
\text { [p.Leu472_His513del]]+[p.Leu472_His513del] } \\
\text { [p.Leu472_His513del]+[r.spl?] } \\
\text { [p.Leu472_His513del]]+[p.Leu472_His513del] } \\
\text { [p.Leu472_His513del]+[?] } \\
\text { [p.Leu472_His513del]]+[?] } \\
\text { [r.spl?]+[r.spl?] } \\
\text { [p.Cys490Tyr]+[?] } \\
\text { [p.Leu472_His513del]+[p.Leu472_His513del] } \\
\text { [p.Cys490Tyr]+[p.Trp590X] } \\
\text { [p.Cys490Tyr]+[p.Cys490Tyr] } \\
\text { [p.Trp425Ser]+[p.Val633X] } \\
\text { [r.spl?]+[?] }\end{array}$ \\
\hline
\end{tabular}

p.301X). These two mutations account for all diagnosed MEB cases in Finland. Screening of 154 Finnish control samples revealed three carriers of the c.1539+1G $\rightarrow$ A founder mutation. All three originated from western Finland, where the incidence of MEB is highest. No carriers were found for the c. $879+5 \mathrm{G} \rightarrow \mathrm{T}$ mutation among 75 control samples studied.

Among the 14 non-Finnish MEB patients, nine different mutations in POMGnTl were identified (table 1). Five patients had homozygous and five compound heterozygous mutations, while in four patients only one mutation was identified. One of the mutations was the c.1539+lG $\rightarrow$ A mutation common in the Finnish patients (see above) and described previously, ${ }^{19}$ and was found in six patients (patients 19-23 and 26) from four different countries. Eight were novel mutations that were not identified in at least 125 controls studied.

Two missense changes $($ c.1274G $\rightarrow$ C, p.Trp425Ser and c. $1496 \mathrm{G} \rightarrow \mathrm{A}$, p.Cys490Tyr) affect the catalytic domain ${ }^{10} 23$ of POMGnTl. Of these the $\mathrm{c} .1469 \mathrm{G} \rightarrow \mathrm{A}$ change was seen in heterozygous form in three patients from the USA and in homozygous form in two Israeli siblings.

One of the mutations predicts protein truncation through a nonsense mutation (c.1796G $\rightarrow$ A, p.Trp590X), and five mutations affect donor or acceptor splice sites, of which at least one produces a premature stop codon. In patient 20 , a c. $879+5 \mathrm{G} \rightarrow \mathrm{A}$ change was identified. Interestingly, the nucleotide affected is the same as in the rare Finnish mutation (see above), but the change is different $(\mathrm{G} \rightarrow \mathrm{A}$ instead of $\mathrm{G} \rightarrow \mathrm{T}$ ). Therefore it is likely to affect splicing, even though this could not be verified, as no RNA was available from this patient. Patient 24 was compound heterozygous for two different mutations affecting the highly conserved $G$ nucleotide of the splice donor site of intron 21 (c.1895+lG $\rightarrow \mathrm{T}$ and c. $1895+1 \mathrm{G} \rightarrow \mathrm{A}$ ). As no RNA was available from this patient we were not able to investigate the predicted altered splicing on cDNA level. Moreover, the c.1285-2A $\rightarrow$ G change in patient 32 affecting the highly conserved A nucleotide of the splice acceptor site in intron 15 is likely to influence splicing, although this was not experimentally verified. In patient 31, we identified a 4 bp deletion of GTGA, normally existing in two copies in the immediate sequence downstream of exon 21 . This change was shown to result in lack of splicing at c.1895+l and retention of the whole mutated intron (data not shown), predicting immediate truncation of the protein (p.Val633X).

To illustrate the extent of clinical variation among patients homozygous for the Finnish founder mutation, we describe two patients with different severity of the clinical symptoms.

\section{Patient 1}

The patient was first examined at the age of two months because of hypotonia and poor vision. Myopia of $-6 \mathrm{D}$ was found and she was given spectacles, which improved her visual contact. She learned to roll over at the age of one year and to walk without support at four years. At her present age of 12 years she walks several hundred metres without support, she can feed herself, can use the toilet, and communicates with sounds and a communicator. MRI at the age of three years showed a flat pons, polymicrogyria, paychygyria, and slightly enlarged lateral ventricles (identical to fig $2 \mathrm{~B}$ ). Her muscle biopsy at the age of one year showed a few regenerating fibres and slightly increased variation in fibre size. Her creatine kinase (CK) was 781 U/l (upper limit of normal $170 \mathrm{U} / \mathrm{l}$ ) at the age of one year. She has epilepsy since the age of nine years and has short absence seizures in spite of drug treatment. She has myopia of $-12 \mathrm{D}$, and a cataract has been operated on.

\section{Patient 2}

This 37 year old man was born after an uneventful pregnancy. He was floppy and severely neurologically abnormal with poor contact from birth. His head circumference was at 0 SD while his height followed the -1.5 SD curve. A pneumonecephalogram at the age of six months revealed enlarged lateral ventricles. Treatment with acetazolamide was started. His motor development has been minimal; by the age of three he had learned to roll from side to side and grasp with his hands. He has been treated for seizures since the age eight months. He could vocalise but contact with the surrounding world was minimal. He was placed in an institution for the mentally retarded at the age of four years. An ophthalmological examination at the age of 17 years revealed cataract in his right and myopia of $-25 \mathrm{D}$ in his left eye. He was examined by us at the age of 28 years. He was bedridden, with spasticity and contractures in the limbs, and he could roll his head from side to side. His CK was $1322 \mathrm{U} / \mathrm{l}$ (upper normal $220 \mathrm{U} / \mathrm{l}$ ). His brain MRI is shown in fig 2A. He had cataracts in both eyes, and on MRI his left optic bulb was abnormally shaped with a sagittal length of $30 \mathrm{~mm}$, while the right eye was microphthalmic. Muscle biopsy showed fat infiltration, mild variation of fibre size, atrophic fibres, and a few regenerating fibres.

\section{DISCUSSION}

The clinical spectrum of diseases caused by defective protein glycosylation has rapidly increased since the description of the CDG syndrome. ${ }^{24}$ The diseases involving $\mathrm{N}$-glycosylation have a wide spectrum of clinical phenotypes-for example, 

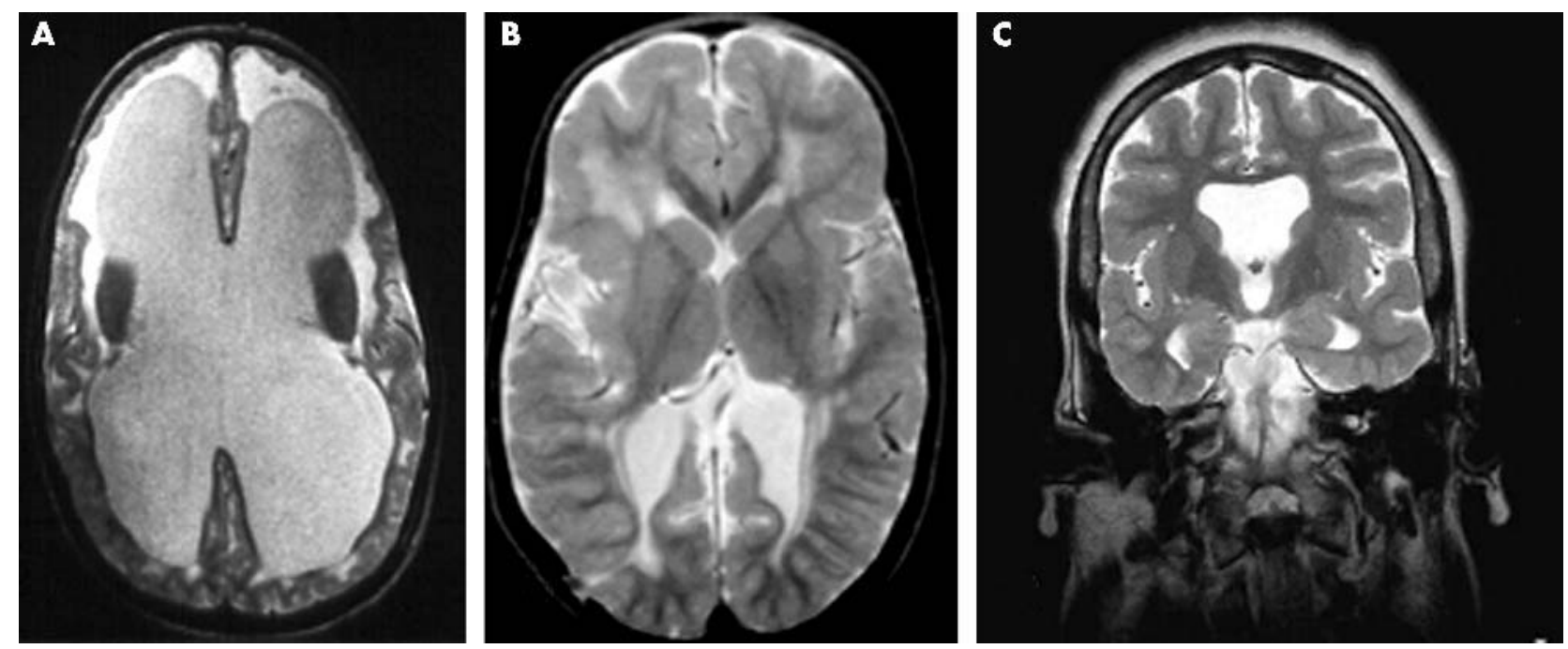

Figure 2 T2 weighted images of three patients with muscle-eye-brain disease (MEB) homozygous for the Finnish founder mutation. (A) In an axial image of a clinically severe case, the lateral ventricles are extremely large and the interventricular septum is missing. There is hyperintensity and volume loss of the entire white matter. The abnormal cortex is clearly visible, especially in the frontal lobes. (B) In a clinically intermediate patient with a ventriculoperitoneal shunt, an axial image shows white matter hyperintensity around the ventricles in the frontal and peritrigonal area. The rest of the white matter shows normal intensity. Note the cobblestone pattern of the frontal cortex. (C) In a clinically mild case, a coronal image shows mild dilatation of the ventricles with absent interventricular septum. The white matter intensity is normal. The abnormal cortex is again seen in the frontal lobes.

mental retardation and multiple organ involvement. ${ }^{25}{ }^{26}$ After the discovery of an $O$-mannosylation defect behind MEB, several other muscular dystrophies, including WWS and two new types of limb girdle dystrophy, were found to belong to the same category. ${ }^{27}$ Fukutin, the protein defective in FCMD, is also postulated to play a part in glycosylation. ${ }^{13}$

We have studied several MEB patients of various ethnic origins, and here describe the Finnish founder POMGnT1 mutation as well as nine novel mutations underlying MEB in patients from different countries, increasing the number of published POMGnTl mutations in MEB to 22 (fig 1). The Finnish founder mutation, c. $1539+\mathrm{lG} \rightarrow \mathrm{A}$, has previously been reported in patients from Turkey, Belgium, and the USA. ${ }^{10}{ }^{19}$ We also detected it in six patients of north European or north American origin, in addition to the 19 Finnish patients. This is the most common single POMGnTl mutation underlying MEB. All other mutations reported to date, with the exception of the p.Cys490Tyr missense mutation identified in three families in this study, have been encountered in single families. Haplotype analysis suggests a single origin for the $\mathrm{c} .1539+\mathrm{GG} \rightarrow$ A mutation in the Finnish population. As the majority of patients with this mutation originate from Scandinavia or northern Europe, it is likely that these patients share a common origin for the mutation. Haplotype data available in seven of nine non-Finnish chromosomes bearing the c.1539+1G $\rightarrow$ A mutation support a common origin with the Finnish mutation in four chromosomes (data not shown). In three Swedish chromosomes an analysis with markers closer to POMGnTl would be needed to find out whether their "Finnish" haplotype is restricted to a very short segment by historical recombinations or whether these mutations have independent origins. In four patients only one disease allele was identified. As no RNA was available from these patients, mutations in introns or regulatory regions affecting splicing or transcript levels may have remained undetected. Moreover, our mutation screening protocol does not allow detection of heterozygous genomic rearrangements unless they result in aberrant PCR fragments. The 22 POMGnTl mutations in MEB described to date are evenly located throughout the gene, with no obvious mutational hotspots. In the light of previous studies, ${ }^{10}{ }^{19} 20$ it is likely that the mutations identified by us result in loss of function of POMGnTl, as they either affect amino acids in the catalytic domain, or predict truncated proteins.

Every successful genetic mapping has to solve the question of clinical delineation of patients selected for the study. This question has continuously shadowed the molecular genetic studies of WWS and MEB, because both diseases are rare worldwide, and the clinical similarities and differences are confusing. Now that the clinical ${ }^{5}$ and genetic identity of these syndromes has been clarified, the question remains as to how the different mutations within each group affect the clinical phenotype. Based on a mutation study of patients of different ethnic origins, Taniguchi and co-workers ${ }^{19}$ suggested that the mutations near the $5^{\prime}$ terminus cause more severe clinical symptoms than the ones near the 3' terminus. However, based on our data on the Finnish MEB patients, all except one of whom are homozygous for a single mutation, this is not the case. As exemplified with the two short case reports presented in this paper, Finnish patients homozygous for the founder mutation show wide variation in their phenotypic spectrum, with patient 1 having the mildest clinical manifestations and patient 2 representing the severe end of the clinical spectrum. The variation seen in the Finnish patients equals that seen in our molecularly defined nonFinnish MEB patients and in those reported earlier. ${ }^{10}{ }^{19}$ All Finnish patients were severely handicapped, but some learned to take steps and say a few words, while others remained bed ridden with no communication or contact with the outside world. Some of the patients who have learned to walk have lost this ability.

While comparing clinical phenotypes of MEB patients, two aspects should be kept in mind. First, some features like the ocular symptoms and dystrophic changes in the muscle are progressive. Second, the treatment of severely handicapped persons has improved during the past 30 years. Children, in whom hydrocephalus has been shunted early, myopia corrected, and epilepsy treated, and who are actively rehabilitated have a better chance of using their potential. Therefore one should be cautious while comparing patients from whom limited clinical data are available. We identified no consistent genotype-phenotype correlations in the 
non-Finnish patients studied, which is not unexpected in the case of loss of function mutations. Based on the clinical spectrum in the Finnish MEB patients, the largest cohort of patients homozygous for a single POMGnTl mutation, it is likely that in addition to mutations in this gene, other factors-both genetic and non-genetic-contribute to the observed phenotypic variation.

\section{Data access}

The POMGnTl mutations described have been deposited in Human Gene Mutation Database (http://archive.uwcm.ac.uk/ uwcm/mg/hgmd0.html).28

\section{ACKNOWLEDGEMENTS}

We thank the patients and family members who participated in this study, and Sinikka Lindh RN for collecting the samples in Finnish MEB families. Drs Tiziana Battistin, Ignacio Pascual Castroviejo, Gunilla Malm, Paul Uvebrandt, Riina Zordania, and Torstein Vik are thanked for providing the samples from non-Finnish patients. Nina Halla and Tanja Holopainen are acknowledged for their skilful technical assistance. This study was supported by grants from the Sigrid Juselius Foundation, the Folkhälsan Research Foundation, and The Academy of Finland (project 43029). The study was carried out in the Centre of Excellence in Disease Genetics of the Academy of Finland (Project 44870, Finnish Centre of Excellence programme 2000-2005).

\section{Authors' affiliations}

C Diesen, A Saarinen, C Rosenlew, J Dieguez, T Joensuu,

A-E Lehesjoki, Folkhälsan Institute of Genetics, Department of Medical Genetics and Neuroscience Centre, Biomedicum Helsinki, University of Helsinki, Helsinki, Finland

H Pihko, Department of Paediatric Neurology, University of Helsinki B Cormand, Department of Genetics, Faculty of Biology, University of Barcelona, Barcelona, Spain

W B Dobyns, Departments of Human Genetics, Neurology and

Pediatrics, University of Chicago, Chicago, Illinois, USA

L Valanne, Department of Radiology, University of Helsinki

Conflicts of interest: none declared

$C$ Diesen and $A$ Saarinen made an equal contribution to this work

Correspondence to: Dr Anna-Elina Lehesjoki, Folkhälsan Institute of Genetics, Biomedicum Helsinki, PO Box 63 (Haartmaninkatu 8), FIN00014 University of Helsinki, Finland; anna-elina.lehesjoki@helsinki.fi

\section{REFERENCES}

1 Santavuori P, Leisti J, Kruus S. Muscle, eye and brain disease: a new syndrome. Neuropediatrie 1977;8(suppl):553-8.

2 Norio R. Finnish Disease Heritage I: characteristics, causes, background. Hum Genet 2003;112:441-56

3 Santavuori P, Somer H, Sainio K, Rapola J, Kruus S, Nikitin T, Ketonen L, Leisti J. Muscle-eye-brain disease (MEB). Brain Dev 1989;1 1:147-53.

4 Pihko H, Lappi M, Raitta C, Sainio K, Valanne L, Somer H, Santavuori P. Ocular findings in muscle-eye-brain (MEB) disease: a follow up study. Brain Dev 1995; 17:57-61

5 Cormand B, Pihko H, Bayes M, Valanne L, Santavuori P, Talim B, GershoniBaruch R, Ahmad A, van Bokhoven H, Brunner HG, Voit T, Topaloglu H Dobyns WB, Lehesjoki AE. Clinical and genetic distinction between WalkerWarburg syndrome and muscle-eye-brain disease. Neurology 2001;56:1059-69.

6 Valanne L, Pihko H, Katevuo K, Karttunen P, Somer H, Santavuori P. MRI of the brain in muscle-eye-brain (MEB) disease. Neuroradiology 1994;36:473-6.
7 Haltia M Leivo I, Somer H, Pihko H, Paetau A, Kivelä T, Tarkkanen A, Tomé F, Engwall E, Santavuori P. Muscle-eye-brain disease. A neuropathological study. Ann Neurol 1997;41:173-80

8 Dobyns WB, Pagon RA, Armstrong D, Curry CJ, Greenberg F, Grix A, Holmes LB, Laxova R, Michels WV, Robinow M, et al. Diagnostic criteria for Walker-Warburg syndrome. Am J Med Genet 1989;32:195-210.

9 Fukuyama Y, Osawa M, Suzuki, H. Congenital progressive muscular dystrophy of the Fukuyama type-clinical, genetic and pathological considerations. Brain Dev 1981;3:1-29.

10 Yoshida A, Kobayashi K, Manya H, Taniguchi K, Kano H, Mizuno M, Inazu T, Mitsuhashi H, Takahashi S, Takeuchi M, Herrmann R, Straub V, Talim B, Voit T, Topaloglu H, Toda T, Endo T. Muscular dystrophy and neuronal migration disorder caused by mutations in a glycosyltransferase, POMGnT1 Dev Cell 2001;1:717-24.

11 Beltrán-Valero de Bernabé D, Currier S, Steinbrecher A, Celli J, van Beusekom E, van der Zwaag B, Kayserili H, Merlini L, Chitayat D, Dobyns WB, Cormand B, Lehesjoki A-E, Cruces J, Voit T, Walsh CA, van Bokhoven $H$, Brunner HG. Mutations in the O-mannosyltransferase gene POMTl give rise to the severe neuronal migration disorder Walker-Warburg syndrome. Am J Hum Genet 2002;71:1033-43.

12 Kobayashi K, Nakahori Y, Miyake M, Matsumura K, Kondo-lida E, Nomura Y, Segawa M, Yoshioka M, Saito K, Osawa M, Hamano K, Sakakihara Y, Nonaka I, Nakagome Y, Kanazawa I, Nakamura Y Tokunaga K, Toda T. An ancient retrotransposal insertion causes Fukuyamatype congenital muscular dystrophy. Nature 1998;394:388-92.

13 Aravind L, Koonin EV. The fukutin protein family-predicted enzymes modifying cell-surface molecules. Curr Biol 1999;9:R836-7.

14 Hayashi YK, Ogawa M, Tagawa K, Noguchi S, Ishihara T, Nonaka I, Arahata K. Selective deficiency of alpha-dystroglycan in Fukuyama-type congenital muscular dystrophy. Neurology 2001;57:115-21.

15 Michele DE, Barresi R, Kanagawa M, Saito F, Cohn RD, Satz JS, Dollar J, Nishino I, Kelley RI, Somer H, Straub V, Mathews KD, Moore SA, Campbell KP. Post-translational disruption of dystroglycan-ligand interactions in congenital muscular dystrophies. Nature 2002;418:417-22.

16 Kano H, Kobayashi K, Herrmann R, Tachikawa M, Manya H, Nishino I, Nonaka I, Straub V, Talim B, Voit T, Topaloglu H, Endo T, Yoshikawa H, Toda T. Deficiency of alpha-dystroglycan in muscle-eye-brain disease. Biochem Biophys Res Commun 2002;291:1283-6.

17 Longman C, Brockington M, Torelli S, Jimenez-Mallebrera C, Kennedy C, Khalil N, Feng L, Saran RK, Voit T, Merlini L, Sewry CA, Brown SC, Muntoni F. Mutations in the human LARGE gene cause MDC1D, a novel form of congenital muscular dystrophy with severe mental retardation and abnormal glycosylation of alpha-dystroglycan. Hum Mol Genet 2003;12:2853-61.

18 Grewal PK, Holzfeind PJ, Bittner RE, Hewitt JE. Mutant glycosyltransferase and altered glycosylation of alpha-dystroglycan in the myodystrophy mouse. Nat Genet 2001;28:151-4

19 Taniguchi K, Kobayashi K, Saito K, Yamanouchi H, Ohnuma A, Hayashi YK, Manya $\mathrm{H}$, Kyu Jin D, Lee M, Parano E, Falsaperla R, Pavone $P$, Van Coster R, Talim B, Steinbrecher A, Straub V, Nishino I, Topaloglu H, Voit T, Endo T, Toda T. Worldwide distribution and broader clinical spectrum of muscle-eyebrain disease. Hum Mol Gen 2003;12:527-34.

20 Manya H, Sakai K, Kobayashi K, Taniguchi K, Kawakita M, Toda T, Endo T. Loss-of-function of an $\mathrm{N}$-acetylglucosaminyltransferase, $\mathrm{POMGnT1}$, in muscleeye-brain disease. Biochem Biophys Res Commun 2003;306:93-7.

21 Gershoni-Baruch R, Mandel H, Miller B, Sujov P, Braun J. Walker-Warburg syndrome with microtia and absent auditory canals. Am J Med Genet 1990;37:87-91.

22 Bassam BJ, Caetano-Anolles G, Gresshoff PM. Fast and sensitive silver staining of DNA in polyacrylamide gels. Anal Biochem 1991;196:80-3

23 Unligil UM, Zhou S, Yuwaraj S, Sarkar M, Schachter H, Rini JM. X-ray crystal structure of rabbit $\mathrm{N}$-acetylglucosaminyltransferase $\mathrm{I}$ : catalytic mechanism and a new protein superfamily. EMBO J 2000;19:5269-80.

24 Stibler $\mathrm{H}$, Jaeken J. Carbohydrate deficient serum transferrin in a new systemic hereditary syndrome. Arch Dis Child 1990;65:107-11.

25 Jaeken J, Matthijs G. Congenital disorders of glycosylation. Annu Rev Genomics Hum Genet 2001;2:129-51.

26 de Lonlay P, Seta N, Barrot S, Chabrol B, Drouin V, Gabriel BM, Journel H, Kretz M, Laurent J, Le Merrer M, Leroy A, Pedespan D, Sarda P, Villeneuve N Schmitz J, van Schaftingen E, Matthijs G, Jaeken J, Korner C, Munnich A, Saudubray JM Cormier-Daire V. A broad spectrum of clinical presentations in congenital disorders of glycosylation I: a series of 26 cases. J Med Genet 2001;38:14-19.

27 Muntoni F, Brockington M, Blake DJ, Torelli S, Brown SC. Defective glycosylation in muscular dystrophy. Lancet 2002;360:1419-21.

28 Stenson PD, Ball EV, Mort M, Phillips AD, Shiel JA, Thomas NS, Abeysinghe S, Krawczak M, Cooper DN. Human Gene Mutation Database (HGMD): 2003 update. Hum Mutat 2003;21:577-81. 